\title{
Reports and Further References
}

\author{
Stephen Juhasz, Frithiof I. Niordson and Peter Eberhard
}

\section{A. Frequency, Availability}

The IUTAM Reports were issued annually with one exception. There was a combined three-year report for the years 1954-55-56. IUTAM was formally established in 1946 and the first issue was published for the year 1948. The reports are usually printed during the calendar year following the year to which they refer. The last available report used for this edition of the book is for the 2014 calendar year. Copies of reports have been available from the IUTAM Secretariat and all reports are now available in scanned form on the IUTAM website www.iutam.org.

S. Juhasz (1913-2013)

Southwest Research Institute, San Antonio, USA

F.I. Niordson (1922-2009)

Technical University of Denmark, Lyngby, Denmark

P. Eberhard (*1966)

University of Stuttgart, Stuttgart, Germany

(C) The Author(s) 2016

P. Eberhard and S. Juhasz (eds.), IUTAM,

DOI 10.1007/978-3-319-31063-3_10 

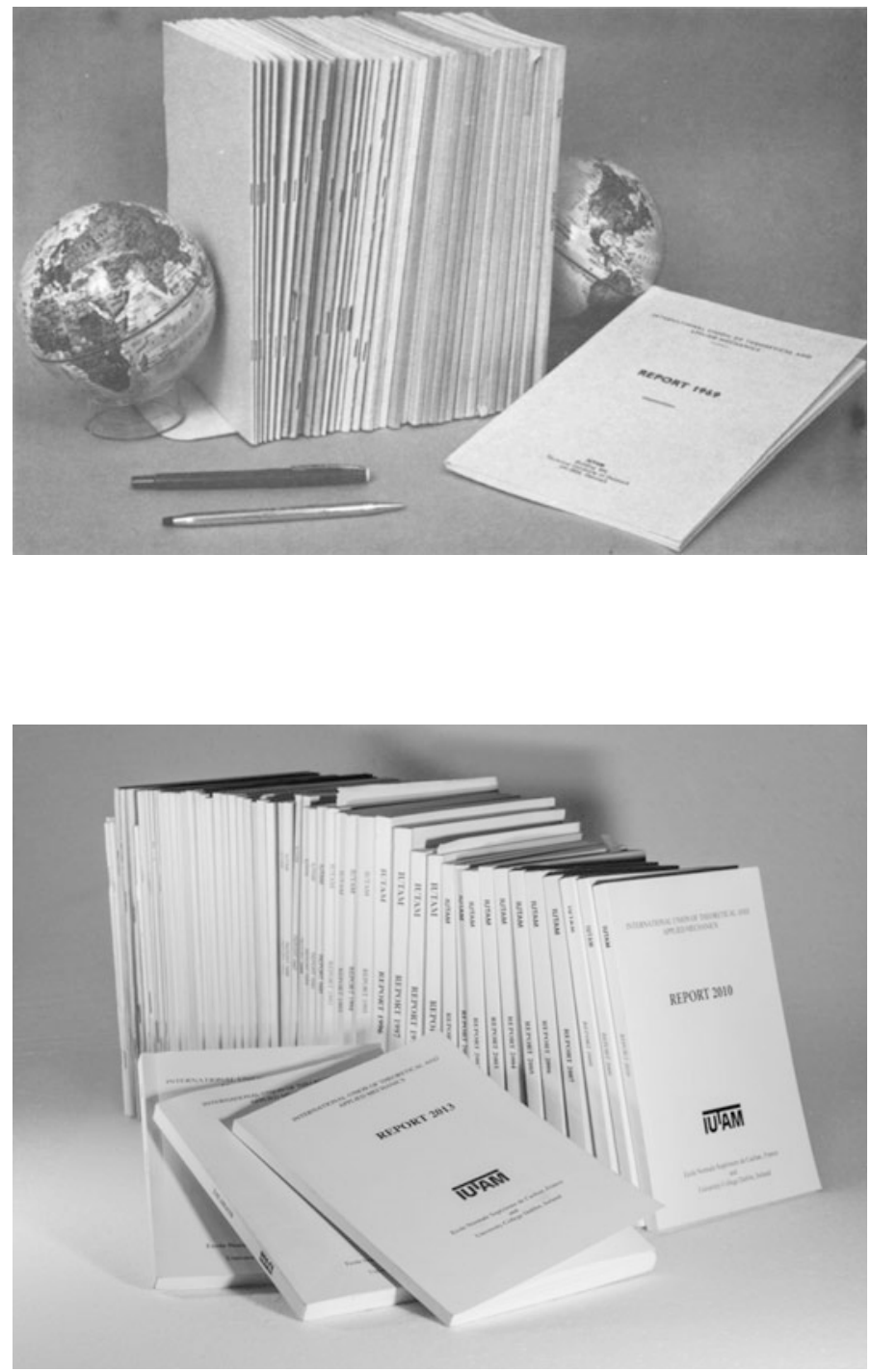


\section{B. Standardization}

Unlike the IUTAM Proceedings, efforts have been made from the beginning, most likely by the General Secretaries, to achieve standardization in IUTAM Reports. The first phase was the standardization of size of the report and of the cover $(16 \times 23.5 \mathrm{~mm}$, with ivory color). The second phase was the standardization of the information on the cover.

1. Information on title page in, English (as is majority of reports)

2. On top "International Union of Theoretical and Applied Mechanics."

3. In the center "Report..."

4. On the bottom the IUTAM logo with the address of the Secretariat.

The third phase of the standarization dealt with the content. Until 1968 the content of the report centered around the Bureau and General assembly meetings, followed by the appendices in somewhat arbitrary fashion. With the 1969 report the grouping and sequencing has been improved. Also, an alphabetical "List of Addresses" of persons associated with IUTAM was introduced. From 1984, the spine of the volume is lettered "IUTAM" and also with "Report 1984."

In the current format the first part is devoted to IUTAM activities with the record of the Annual General Assembly meetings given only in summary form. The second part contains reports with one or two exceptions relating to affiliated and adhering organizations and also detailed reports about all symposia of the corresponding year. The third part contains IUTAM statutes, resolutions, rules and procedures. This section concludes with a list of publications and list of names and addresses. The consecutive reports basically maintained the above format.

\section{Further References}

Bibliographical details of Proceedings of IUTAM Congresses, Symposia, and Reports are provided in the appendix. They have been the main sources of information for this book. Further interesting reading related to the history of IUTAM can be found in the following references.

Alkemade, A.J.Q., IUTAM 1946-1996; Fifty Years of Impulse to Mechanics. Dordrecht, Kluwer, 1996.

Battimelli, G., The Mathematician and the Engineer: Statistical Theories of Turbulence in the 20's. Rivista di storia delle scienze mediche e naturali 1:73-94, 1984.

Drucker, D.C. and Lee, E.H., Notes on the Eighth International Congress on Theoretical and Applied Mechanics, August 20 to 28, 1952, Istanbul, Turkey. Applied Mechanics Reviews 5: 497-498, 1952.

Goodstein, J.R., and Kopp, C., eds. The Theodore von Karman Collection at the California Institute of Technology; Guide to the original collection and a microfiche edition. Pasadena, California Institute of Technology, 1981. (also at resolver.caltech.edu/CaltechBOOK:1981.004) 
Juhasz, S., Famous Mechanics Scientists; Notes on AMR-RZM Exhibit/XIII IUTAM Congress, Moscow 1972. Applied Mechanics Reviews 26: 145-160, 1973.

Juhasz, S., From Delft to Delft. (AMR Report no. 59). San Antonio, Applied Mechanics Reviews, 1976.

Juhasz, S., International Congresses of Theoretical and Applied Mechanics: The First Half Century. Applied Mechanics Reviews 30: 1323-1324, 1977.

Juhasz, S., Mechanics in Action; XV IUTAM Congress, Toronto 1980. Applied Mechanics Reviews 34: 317, 1981.

Schiehlen, W. and van Wijngaarden, L., eds. Mechanics at the Turn of the Century. Aachen, Shaker Verlag, 2000.

von Karman, T. and Edson, L., The Wind and Beyond, pp. 104-105 and pp. 294-295. Boston, Little, Brown and Co., 1967.

Open Access This chapter is distributed under the terms of the Creative Commons AttributionNoncommercial 2.5 License (http://creativecommons.org/licenses/by-nc/2.5/) which permits any noncommercial use, distribution, and reproduction in any medium, provided the original author(s) and source are credited.

The images or other third party material in this chapter are included in the work's Creative Commons license, unless indicated otherwise in the credit line; if such material is not included in the work's Creative Commons license and the respective action is not permitted by statutory regulation, users will need to obtain permission from the license holder to duplicate, adapt or reproduce the material. 